\title{
Percepción de los microempresarios del sector calzado ubicados en la comuna nueve de San José de Cúcuta, sobre la aplicación del Marco

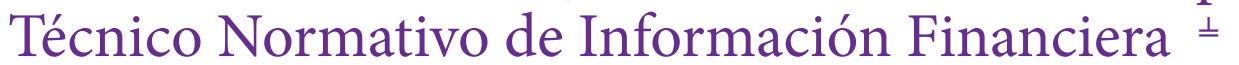

\author{
Perception of footwear industry micro-entrepreneurs located in Commune Nine at San Jose de Cucuta \\ (Colombia) regarding the implementation of the Technical Regulatory Framework for Financial \\ Reporting
}

Luz Estela Durán Caicedo ${ }^{1 *}$, Lic., MSc

${ }^{1}$ Docente Universidad Libre Seccional Cúcuta - Facultad de Contaduría. MSc. Prácticas Pedagógicas Universidad Francisco de Paula Santander. Especialista en Revisoría Fiscal Universidad Libre Seccional Cúcuta - Facultad de Contaduría. Doctorante en Ciencias Contables Universidad de los Andes ULA - Mérida Estado Táchira-Venezuela. Email: luz.duran@unilibrecucuta.edu.co.

(Aceptado: 17 de noviembre de 2014)

\section{Resumen}

El trabajo tuvo como objetivo determinar las percepciones que tienen los propietarios de las microempresas del sector Calzado, ubicadas en la Comuna 9 de la ciudad de San José de Cúcuta, sobre la Aplicación del Marco Técnico Normativo de Información Financiera (MTNIF). Metodológicamente, el estudio se desarrolló bajo el enfoque cualitativo, presentando un carácter descriptivo, pues se seleccionó una muestra de 45 microempresas ubicadas en el escenario objeto de la investigación. La recopilación de la información, se realizó a través de la aplicación de una entrevista semiestructurada, cuyos resultados se utilizaron para la construcción de categorías y subcategorías procesadas a través de matrices reconstructivas. Los resultados demuestran, que los microempresarios seleccionados desconocen el MTNIF, dado que hasta el momento no han aplicado las exigencias del Decreto 2706. En consecuencia, se evidencia la importancia de capacitar a los microempresarios de este sector sobre las exigencias del MTNIF para la presentación de los estados financieros.

Palabras clave: microempresas, San José de Cúcuta, Marco Técnico Normativo de Información Financiera, Decreto 2706.

\footnotetext{
${ }^{ \pm}$Para citar este artículo: Durán Caicedo, LE. Percepción de los microempresarios del sector calzado ubicados en la comuna nueve de San José de Cúcuta sobre la aplicación del Marco Técnico Normativo de Información Financiera. RHS. Revista. Humanismo. Soc, Volumen 2 (2): 11-23.

*Autor para correspondencia: Luz Estela Durán Caicedo. Facultad de Contaduría, Universidad Libre. Correo electrónico: luz.duran@ unilibrecucuta.edu.co.Facultad de Ciencias empresariales.E-mail: jcardona@remington.edu.co.
} 


\begin{abstract}
This study aimed to determine the perceptions of microenterprise owners of the footwear sector at Commune 9 in the city of San Jose de Cucuta about the application of the Technical Regulatory Framework for Financial Reporting (MTNIF). Methodologically, this was a qualitative descriptive study based on a sample of 45 micro-enterprises. A semi-structured interview was used to collect the information. Categories and subcategories were created and processed through reconstructive matrices. The results show that entrepreneurs ignore the MTNIF given that they have failed to implement the requirements of Decree 2706. Consequently, this study evidences the importance of training microentrepreneurs of this sector on the MTNIF requirements for filing their financial statements.
\end{abstract}

Key words: Decree 2706, micro-enterprises, San José de Cúcuta, Technical Regulatory Framework for Financial Reporting.

\title{
Introducción
}

En el 2012, el Gobierno de Colombia publicó el Decreto 2706, el cual establece en el Artículo 1, el Marco Técnico Normativo de Información Financiera para las microempresas, proponiendo un régimen simplificado de contabilidad de causación, basado en los requerimientos de reconocimiento, medición, presentación e información que se requiere revelar en los estados financieros de las microempresas pertenecientes al grupo 3 de la normatividad vigente.

Bajo esta orientación, la presente investigación se orientó a determinar las percepciones que tienen los propietarios de las microempresas del sector Calzado, ubicadas en la Comuna 9 de la ciudad de San José de Cúcuta, sobre la Aplicación del Marco Técnico Normativo de Información Financiera. El análisis de estas percepciones, constituyó la base para determinar las necesidades de capacitación e implementación de proyectos de extensión por parte del sector objeto de estudio.

Metodológicamente, la investigación se desarrolló bajo un enfoque cualitativo. La población, se configuró a partir de las 80 microempresas del sector calzado ubicadas en el escenario seleccionado como objeto de investigación, que cumplen los requisitos exigidos por el Decreto 2706 del 2012 para pertenecer al grupo 3: a) contar con una planta de personal no superior a diez (10) trabajadores; b) poseer activos totales, excluida la vivienda, por un valor inferior a quinientos (500) salarios mínimos mensuales legales vigentes (SMMLV); c) percibir ingresos brutos anuales inferiores a 6.000 SMMLV ); y d) estar inscritos en la Cámara de Comercio de la ciudad de San José de Cúcuta.

En este contexto, la muestra estuvo conformada por 45 microempresas, a cuyos propietarios, gerentes y administradores se les aplicó una entrevista semiestructurada (no formalizada) para la recolección de la información, a partir de la cual se establecieron categorías y subcategorías emergentes procesadas en matrices reconstructivas.

El trabajo se estructuró en cuatro secciones: la primera, aborda las Normas internacionales de información financiera aplicadas a las PYMES, enfatizando en las diversas concepciones que se han utilizado del término PYMES, así como en la normativa internacional propuesta por el IASB, para la presentación de los estados financieros de estas empresas; en la segunda, se presenta la concepción de PYMES sustentada en la legislación colombiana; en la tercera, se expone la metodología empleada para el desarrollo investigativo; en la cuarta, se muestran los resultados del estudio y; en la quinta, se presentan a modo de conclusiones, las reflexiones finales del estudio.

\section{La Norma Internacional de Información Financiera aplicada a las PYMES}

Las PYMES se han abordado como pequeñas empresas que tienen sus particularidades en cuanto 
a características, funcionamiento, organización, conducta y espíritu empresarial (Storey, citado por Gatto, 1993).

Al respecto Rivero, Ávila y Quintana (citados por Tunal, 2003: p.83), exponen que el término microempresa abarca una pequeña unidad socioeconómica que realiza actividades de producción, comercio o prestación de servicios, la cual no requiere de grandes inversiones de capital, se adapta con facilidad al cambio y, pueden orientar acciones para insertarse en el mercado con mayor rapidez y facilidad que otras empresas.

Los autores citados, enfatizan que el tamaño que presentan las microempresas: a) tiene incidencias en los niveles de productividad y eficiencia; b) induce al desarrollo de procesos de innovación; c) facilita la identificación de nichos de mercado; d) promueve la adopción de nuevas tecnologías; e) conduce a la generación de ventajas competitivas; f) facilita la entrada al mercado para competir en los sectores donde existe una demanda insatisfecha; g) permite la prestación de mejores servicios; h) contribuye a potenciar el talento empresarial y; i) genera empleos.

Al analizar esta definición Tunal (2003) y González (2005), expresan que la utilización del término micro resulta ambiguo, dado que en primer lugar, el tamaño de la microempresa por sí solo no conduce al alcance de los aspectos socioeconómicos relacionados con la productividad, la innovación, la competitividad, el empleo, entre otros, y en segundo lugar, no se establece una unidad de comparación, lo cual conduce a la generación de algunas interrogantes como:

¿Pequeña en relación a qué? ¿Una empresa de 500 empleados es pequeña con relación a una trasnacional? ¿A caso la microempresa es sinónimo de pequeña empresa? Si es así ¿por qué razón se diferencia a las empresas micro de las pequeñas? (Tunal, 2003, p. 83).

En tal sentido, también cabe destacar que aún cuando en el campo académico no existe una definición comúnmente aceptada del término PYME, éste presenta un amplio alcance a nivel internacional, siendo utilizado en los diversos países para hacer referencia a las pequeñas y medianas empresas.

Cada país ha elaborado su propia definición, en función de criterios cualitativos y cuantitativos. Los cualitativos comprenden los aspectos relacionados con la propiedad, el tipo de actividad y, el nivel de participación en el mercado; mientras que los de carácter cuantitativo abarcan el ingreso, el valor de los activos, el capital social, el número de empleados, entre otros.

Sobre este aspecto Tunal (2003, p.81), afirma que frecuentemente para la clasificación de las PYMES, se han utilizado los aspectos cuantitativos basados en el número de trabajadores. No obstante:

Se reconoce que las nuevas clasificaciones que se hace de las empresas comienza a tener componentes vinculados con lo cualitativo, (...) El agrupamiento de las empresas a través de lo cualitativo implica el desarrollo de conceptos, intelecciones y comprensiones que parten de las pautas de los datos, generando así una clasificación holística sustentada en los efectos que producen las empresas en términos de sus características de composición y sus marcos de referencia.

En este escenario, con el propósito de obtener la información general, así como otros tipos de información financiera de las PYMES, entidades privadas y entidades sin obligación publica de rendir cuenta, el Consejo de Normas Internacionales de Contabilidad (IASB), ha formulado la Norma Internacional de Información Financiera (NIIF para PYMES), la cual debe ser aplicada a los estados financieros de estas empresas. (IASB, 2009).

Concretamente, la Norma Internacional de Información Financiera en la sección 1, define las PYMES como pequeñas y medianas entidades que: (a) no tienen la obligación pública de rendir cuentas, y (b) publican los estados financieros con propósito de presentar información general para los usuarios externos. Asimismo, se consideran como usuarios externos los propietarios que no realizan actividades de gestión de la empresa, los acreedores actuales o potenciales, así como las agencias de calificación crediticia.

Posteriormente, en la sección 2 de la norma, se establece que los objetivos de los estados financieros de las PYMES se orientan a:

proporcionar información sobre la situación financiera, el rendimiento y los flujos de efectivo de la entidad que sea útil para la toma de decisiones económicas de una amplia gama de usuarios que no están en condiciones 
de exigir informes a la medida de sus necesidades específicas de información (IASB, 2009, p. 14).

En estos términos, como se establece en el numeral 2.3, de la sección 2 de la NIIF para PYMES, los estados financieros de estas entidades deben mostrar "los resultados de la administración llevada a cabo por la gerencia: dan cuenta de la responsabilidad en la gestión de los recursos confiados a la misma" (IASB, 2009, p. 14).

La norma también establece que los estados financieros de las PYMES deben elaborarse bajo los siguientes criterios:

- Comprensibilidad: la información financiera debe presentarse e manera comprensible, para todos los usuarios que tienen un conocimiento razonable de las diversas actividades económicas y empresariales desarrolladas por la empresa, así como para los profesionales encargados de realizar las actividades en materia contable.

- Relevancia: la información proporcionada por la empresa en los estados financieros, debe ser relevante para la toma de decisiones de los usuarios.

- Materialidad o importancia relativa: la información es material y relevante, cuando su omisión o su presentación errónea en los estados financieros, influye en las decisiones económicas que los usuarios tomen a partir de los estados financieros.

- Fiabilidad: la información proporcionada en los estados financieros debe ser fiable y para presentar fielmente lo que se pretende representar, no debe estar cargada de errores significativos y sesgo.

- La esencia sobre la forma: las transacciones, sucesos y demás condiciones de la entidad deben contabilizarse y presentarse considerando además de los aspectos legales, la esencia de la misma.

- Prudencia: hace referencia a la precaución que deben tener los profesionales de la contabilidad, al momento de realizar los juicios y efectuar las estimaciones requeridas para la presentación de los estados financieros en condiciones de incertidumbre, de tal manera, que los activos o los ingresos no se expresen de manera sobrestimada o sobrevalorada y, los pasivos o los gastos no se emitan en defecto.

- Integridad: la información financiera debe presentarse completa, considerando la importancia relativa y el costo.

- Comparabilidad: los usuarios de la información financiera deben tener capacidad para comparar los estados financieros de una entidad a lo largo del tiempo, en la búsqueda de identificar las tendencias de la situación financiera, así como el rendimiento financiero de la entidad.

- Oportunidad: la información financiera debe influir en las decisiones económicas de los usuarios.

- Equilibrio entre costo y beneficio: los beneficios derivados de la presentación de la información deben exceder a los costos de suministrarla.

\section{Las PYMES en la legislación de Colombia}

La Ley 905 publicada en el 2004, conocida en Colombia como la Ley MIPYMES en el Artículo 2, aborda las microempresas como las unidades de explotación económica, conformadas por pequeñas y medianas empresas familiares, donde una persona natural o jurídica realiza actividades de carácter empresarial a nivel rural o urbano en los sectores: agropecuario, industrial, comercial o servicios (Congreso de Colombia, 2004).

En el marco de esta ley, la clasificación de las empresas en microempresas, pequeñas y medianas empresas, se realiza en función del número de trabajadores, así como de los activos totales de la entidad. En este contexto normativo, se define una organización empresarial como:

- Microempresa: cuando se dispone de un personal que no excede a los diez (10) trabajadores y, activos totales registrados por un monto inferior a quinientos uno (501) salarios mínimos mensuales legales vigentes.

- Pequeña empresa: cuando se contratan para el desarrollo de las actividades entre once (11) y cincuenta (50) trabajadores, registrándose activos 
totales por valores comprendidos entre quinientos uno (501) y cinco mil uno (5.001) salarios mínimos mensuales legales vigentes.

- Mediana empresa: cuando se contratan entre cincuenta y uno (51) y doscientos (200) trabajadores, presentándose activos totales por valores comprendidos entre cinco mil uno (5.001) y quince mil (15.000) salarios mínimos mensuales legales vigentes.

Posteriormente, en el 2009 se dicto la ley 1314, cuyo objetivo se centró en regular los principios y normas de contabilidad, la información financiera y el aseguramiento de la información. Específicamente en el artículo 1 se establece que:

el Estado, bajo la dirección del Presidente la República y por intermedio de las entidades a que hace referencia la presente ley, intervendrá la economía, limitando la libertad económica, para expedir normas contables, de información financiera y de aseguramiento de la información, que conformen un sistema único y homogéneo de alta calidad, comprensible y de forzosa observancia, por cuya virtud los informes contables $y$, en particular, los estados financieros, brinden información financiera comprensible, transparente y comparable, pertinente y confiable, útil para la toma de decisiones económicas por parte del Estado, los propietarios, funcionarios y empleados de las empresas, los inversionistas actuales o potenciales $\mathrm{y}$ otras partes interesadas, para mejorar la productividad, la competitividad y el desarrollo armónico de la actividad empresarial de las personas naturales y jurídicas, nacionales o extranjeras. Con tal finalidad, en atención al interés público, expedirá normas de contabilidad, de información financiera y de aseguramiento de información, en los términos establecidos en la presente ley (Congreso de Colombia, 2009, p. 1).

A partir de la aplicación de la ley mencionada, el Estado comenzó a promover la creación de un sistema único, comprensible y homogéneo de alta calidad, manteniendo los principios de equidad, reciprocidad y conveniencia nacional, con el fin de apoyar la internacionalización de las relaciones económicas de las diferentes organizaciones o empresas. De este modo:

la acción del Estado se dirigirá hacia la convergencia de tales normas de contabilidad, de información financiera y de aseguramiento de la información con estándares internacionales de aceptación mundial con las mejores prácticas y con la rápida evolución de los negocios (Congreso de Colombia, 2009, p. 1).

Así mismo, el Consejo Técnico de la Contaduría Pública (CTCP) propuso como referente normativo en materia deinformación financiera, la aplicación delosestándares emitidos por el Consejo de Normas Internacionales de Contabilidad (IASB - International Accounting Standards Board). No obstante, considerando que las IASB no presenta un cuerpo normativo específico para el caso de las microempresas, el CTCP planteó tomar como referente normativo la NIIF para PYMES, simplificando su contenido, en la búsqueda de hacerlo más sencillo y práctico, de tal manera que pudiera ser aplicado a todas las microempresas colombianas.

Específicamente las microempresas, objeto de estudio de la presente investigación, son abordadas en el Decreto 2706 del 2012, del Marco Técnico Normativo de Información Financiera, aplicable a las Microempresas colombianas, elaborado por el Ministerio de Comercio, Industria y Turismo (2012, p.4), en el cual:

Se establece un régimen simplificado de contabilidad de causación para las microempresas, conforme al marco regulatorio dispuesto en el anexo de este decreto. Dicho marco regulatorio establece, además, los requerimientos de reconocimiento, medición, presentación e información a revelar de las transacciones y otros hechos y condiciones de los estados financieros con propósito de información general, que son aquellos que están dirigidos a atender las necesidades generales de información financiera de un amplio espectro de usuarios que no están en condiciones de exigir informes a la medida de sus necesidades específicas de información (Artículo 1).

En relación a la definición de microempresa, en el capítulo 1, numeral 1.2 del Decreto mencionado, se definen tales organizaciones como unidades de producción, que disponen de una planta de personal inferior a diez (10) trabajadores, o presentan activos totales por un valor inferior a quinientos (500) salarios mínimos mensuales legales vigentes.

Sobre la base de lo expuesto, se deduce que el criterio para la clasificación de una empresa como microempresa, se encuentra en el cumplimiento de una de las siguientes condiciones: a) el número de trabajadores, b) el valor de los activos. En este escenario, el Consejo Técnico 
de la Contaduría Pública colombiano, presentó en julio del 2012 un Proyecto de Norma de Información Financiera para las Microempresas, cuyo objetivo se orientó a:

proponer ante el público interesado una norma de contabilidad simplificada, que fuera adecuada a las necesidades de las entidades clasificadas en el grupo tres de acuerdo con el documento del Direccionamiento Estratégico de fecha julio 16 de 2012, elaborado por el CTCP (p.2).

En lo referente a los criterios que deben reunir las empresas para ser categorizadas dentro del grupo 3, el documento de Direccionamiento Estratégico (2012), establece que se ubicarán dentro de esta tipología las entidades que reúnan las siguientes características: a) personas naturales o jurídicas que cumplan los criterios establecidos en el artículo 499 del Estatuto Tributario (ET) y normas posteriores que lo modifiquen; b) microempresas clasificadas como tales según la Ley 590/2000 modificada por la Ley 905/2004, y normas posteriores que la modifiquen o la sustituyan; c) microempresas que no cumplan con los requisitos para ser incluidas en los grupos 1 y 2 , ni en el literal anterior (Consejo Técnico de la Contaduría Pública, 2012).

Posteriormente, en el artículo 1, del Decreto 3019 publicado el 27 de diciembre de 2013, se introduce una modificación del numeral 1.2 del Decreto 2706 (2012), al establecer la normativa aplicable a las personas naturales y jurídicas, que realizan los registros contables. En este escenario, los parámetros que sustentan legalmente la constitución de una microempresa son:

- Contratación de un personal que no excede a los diez (10) trabajadores.

- Disposición de activos totales sin incluir la vivienda, valorados por un monto inferior a los quinientos (500) salarios mínimos mensuales legales vigentes (SMMLV).

- Registro de ingresos brutos anuales inferiores a los seis mil (6.000) salarios mínimos mensuales legales vigentes (SMMLV).

En este Decreto, se consideran trabajadores de una microempresa, las "personas que presten de manera personal y directa servicios a la entidad a cambio de una remuneración, independientemente de la naturaleza jurídica del contrato" (Ministerio de Comercio, Industria y Turismo, 2013, p. 2), excluyéndose de esta categoría, las personas que realizan actividades de servicios como la consultoría y la asesoría externa.

Al respecto, también se precisa que el cálculo del número de trabajadores, así como de los activos totales, se realiza tomando como base el promedio de los doce (12) meses correspondiente al año anterior (I periodo de preparación obligatoria establecido en el artículo 3, del Decreto 2706). En su defecto, se considerará el año "inmediatamente anterior al periodo en el cual se determine la obligación de aplicar el Marco Técnico Normativo de que trata este Decreto, en periodos posteriores al periodo de preparación obligatoria aludido" (Ministerio de Comercio, Industria y Turismo, 2013, p. 2).

En materia contable, el Decreto 2706 comienza a normar la elaboración de los estados de situación financiera de apertura de los microempresarios ubicados en el grupo 3, a partir del 1 de enero de 2014, estableciéndose un período de transición comprendido entre el 1 de enero de 2013 y el 31 de diciembre de 2013. De allí, que la elaboración de los estados de situación financiera de apertura para las microempresas, comenzaron a aplicarse para el período comprendido entre el 1 de enero de 2014 hasta el 31 de diciembre de 2014. Durante este año, el Estado comenzó a medir de acuerdo con los nuevos estándares de contabilidad los activos, los pasivos y el patrimonio de las microempresas ubicadas en el grupo mencionado.

Por ende, los nuevos estándares de contabilidad deben aplicarse a partir del 1 de enero hasta el 31 de Diciembre del 2015, año en el que se deben emitir los primeros estados financieros comparativos, pues cesara la utilización de la norma definida en los Decretos 2649 y 2650 de 1993. En el caso concreto de las nuevas microempresas, la normativa establecida en el Decreto 3019 del 2013, se aplica considerando la información disponible para el momento en que se inician las operaciones de la entidad.

\section{Metodología}

El estudio se abordó desde un enfoque cualitativo, donde el conocimiento se concibe como un acto de 
comprensión, lo cual implica que para la solución del problema planteado, el investigador debe recopilar toda la información relevante, en el lugar o contexto donde ocurre el fenómeno. Posteriormente, esta información se estructura lógica y coherentemente, para presentar los resultados de la investigación.

Durante el proceso de recopilación, categorización e interpretación de los datos, estas operaciones se articulan lógica y sistemáticamente, pues en el desarrollo de la investigación:

la observaciónyla interpretación son inseparables: resulta inconcebible que una se obtenga en total aislamiento de la otra. Toda ciencia trata de desarrollar técnicas especiales para efectuar observaciones sistemáticas y garantizar su interpretación. Sin embargo, sí hay una diferencia de grado. Al principio de la investigación, hay un predominio de la recolección de información sobre la categorización e interpretación; después, a medida que se acerca hacia el final, gradualmente, el balance cambia hacia la categorización e interpretación, con poca recolección de información (Martínez 2006, p. 128- 129).

Considerando el enfoque mencionado, para el abordaje del fenómeno en estudio, se construyo un diseño descriptivo, en la búsqueda de precisar las percepciones de los microempresarios del Sector Calzado ubicados en la Comuna Nueve de la Ciudad de Cúcuta, sobre la Aplicación del Marco Técnico Normativo de Información Financiera exigido por el Decreto 2706 de 2012.

Como lo afirma Kornblit (citado por Koval, 2012), la investigación descriptiva cualitativa permite conocer las situaciones, costumbres y actitudes predominantes a través de la descripción exacta de las actividades, objetos, procesos y personas. Su meta no se limita a la recolección de datos, sino a la comprensión de las relaciones que existen entre dos o más variables. Los investigadores no son meros tabuladores, sino que recogen los datos sobre la base de una hipótesis o teoría, exponen y resumen la información de manera cuidadosa y luego analizan minuciosamente los resultados, a fin de extraer generalizaciones significativas que contribuyan con la generación de conocimiento.

En esta investigación, se consideraron como sujetos de estudio, los propietarios de las microempresas del sector calzado categorizadas según el Decreto 2706 /2012 dentro del grupo 3, ubicadas en la comuna nueve de la Ciudad de Cúcuta, la cual está integrada por los siguientes barrios: Divina Pastora, Belén, Gaitán, La Aurora, Cundinamarca, San Miguel, Loma de Bolívar y Carora.

En función de las características que debe reunir una empresa para ubicarse dentro de la categoría 3, para efectos de la selección de las microempresas se consideraron los siguientes aspectos: planta de personal inferior a diez (10) trabajadores, disponer de activos totales, excluida la vivienda, por un valor inferior a quinientos (500) Salarios Mínimos Mensuales Legales Vigentes (SMMLV), percibir ingresos brutos anuales por un monto inferior a 6.000 Salarios Mínimos Mensuales Legales Vigentes (SMMLV), y estar inscritos en la Cámara de Comercio de la ciudad de Cúcuta (Norte de Santander).

Para la recolección de información, a los sujetos de estudio seleccionados, se les aplicó una entrevista semi estructurada (no estructurada o no formalizada), que permitió registrar información válida y eficaz, basada en las percepciones de los entrevistados sobre la temática de interés para efectos de la investigación, las cuales sirvieron de base para identificar categorías y subcategorías emergentes.

Sobre la base de lo expuesto, en la unidad o escenario seleccionado para la investigación, se detectó la existencia de ochenta (80) microempresas, las cuales conformaron la población objeto de estudio. Como se muestra en la tabla 1, estas organizaciones se codificaron, considerando la ubicación, el sector y la actividad realizada. 
Tabla 1. Codificación de las microempresas del Sector Calzado ubicadas en la Comuna 9 de la ciudad de Cúcuta.

Codificación

$$
\text { Sector }
$$

Carácter empresarial

$\begin{array}{ccc}\text { MCNBDP1 } & \text { Privado } & \text { Calzado } \\ \text { MCNBB2 } & \text { Privado } & \text { Calzado } \\ \text { MCNBG3 } & \text { Privado } & \text { Calzado } \\ \text { MCNBLA4 } & \text { Privado } & \text { Calzado } \\ \text { MCNBC5 } & \text { Privado } & \text { Calzado } \\ \text { MCNBSM6 } & \text { Privado } & \text { Calzado } \\ \text { MCNBLB7 } & \text { Privado } & \text { Calzado } \\ \text { MCNBC8 } & \text { Privado } & \text { Calzado }\end{array}$

A partir de la población total de microempresas (80), se calculó la muestra, tomando un margen de error del 5\% y una heterogeneidad del 50\%, encontrándose un total de cuarenta y cinco (45) microempresas, a cuyos propietarios se les aplicó un cuestionario para determinar a partir de las respuestas de los sujetos de estudio las categorías y subcategorías de análisis. Tal instrumento, se estructuro sobre la base de preguntas desencadenantes que sirvieron de soporte, para realizar posteriormente, una entrevista a los propietarios.

La información recopilada se analizó bajo las fases del método propuesto por Shaw (citado por Martínez; 2006):

- Análisis en sitio: constituyó la primera fase del análisis inductivo y, se realizó en el mismo momento en que se desarrollaban las entrevistas.

- Trascripción de los datos: se configuró como la segunda fase de la investigación, se aplicó al terminar cada entrevista, pues se procedió a su lectura para comprender la información suministrada, en la búsqueda de estructurarla y organizarla, de acuerdo con las dimensiones, variables, y categorías que contribuirían finalmente con la solución del problema de investigación.

- Foco de análisis: en esta fase se procedió al análisis de los datos recopilados, para determinar en qué medida las categorías teóricas existentes se aplican en el campo empírico.
- Análisis profundo de la información: en esta fase se procedió a interpretar y explicar los hechos ubicados en las categorías recopiladas a partir de la entrevista y, de la aplicación de los cuestionarios.

Así mismo, la información recopilada a través de las fases mencionadas, constituyó el fundamento para establecer los códigos emergentes, que sustentaron el análisis de la información, y la formulación de las categorías de análisis, en la búsqueda de clasificar la información registrada, y simplificar el volumen de datos recogidos de las entrevistas. Sobre este aspecto Thiebaut (1998) plantea que:

las categorías son las clasificaciones más básicas de conceptualización, y se refieren a clases de objetos de los que puede decirse algo específicamente; (...) Una categoría es un segmento de elementos singulares, o unidades de sentido, que son relevantes y significativas desde el punto de vista del interés investigativo del autor.

Tales categorías sustentaron la elaboración de matrices reconstructivas, las cuales abarcaron los siguientes códigos emergentes: percepción de propietarios, lo que piensan, lo que creen, lo que conocen, así como las expectativas de las Microempresas en relación a la implementación del Marco Técnico Normativo de Información Financiera. En función de estos códigos, y considerando el testimonio de los propietarios de las Microempresas objeto de estudio, sobre la aplicación del Marco Técnico Normativo de Información Financiera, se construyeron las siguientes categorías de análisis: a. 
Lo qué piensan; b. Lo que creen; c. Lo que conocen y d. Lo que esperan.

\section{Resultados}

\section{Percepciones de propietarios de las microempresas del sector calzado ubicados en la comuna nueves en la ciudad de San José de Cúcuta}

Percepción 1. Lo que conocen los microempresarios sobre la aplicación del Marco Técnico de Información Financiera:

Sobre la base de los testimonios de los propietarios de las microempresas consultadas se procedió a extraer los códigos emergentes, los cuales presentaron algunas regularidades y elementos comunes, que sirvió de base para elaborar una primera aproximación de la percepción que se tiene de la aplicación del Marco Técnico Normativo de Información Financiera.

En tal sentido, la información revela el desconocimiento que tienen los propietarios sobre los propósitos, objetivos y aplicación del Decreto objeto de estudio, pues se registraron respuestas ambiguas, inconsistentes y en algunos casos erradas. A continuación se presentan algunos testimonios encontrados:

- "Es una norma para las empresas de cómo llevar su contabilidad..."

- "No la verdad, no tengo conocimiento sobre este marco normativo..."

- "No, no lo conozco al pie de la letra, pensaría que si solo están para ubicar a las Microempresas dentro de un marco global, pero no se capacita sobre su aplicación el proceso no está siendo retroalimentado. Pues no se toman los correctivos pertinentes".

- "Es la forma en que se presentan los estados financieros de la empresa..."

- "No...no conozco las políticas ni los objetivos"

- "No conozco los objetivos, pero creo que es como unificar la forma en que se presentan los informes financieros..."
- "No, no tengo conocimiento..."

- "Desconozco la información y aplicación de este marco normativo"

- "No puedo opinar por qué no las conozco".

Subsiguientemente, se procedió a sistematizar los testimonios encontrados a partir de las entrevistas, en las matrices reconstructivas para identificar los códigos emergentes, encontrándose la existencia de similitudes entre los códigos, lo cual permitió agruparlos, para construir una matriz, en las que se identificaron categorías y subcategorías, que constituyeron la base para el análisis de las percepciones que tienen los propietarios de las Microempresas del sector calzado que pertenecen al grupo 3 .

Percepción 2. El Marco Técnico Normativo de Información Financiera como instrumento que direcciona y regula la información financiera de las microempresas:

Sobre este aspecto, cabe destacar que la información recopilada en el escenario objeto de estudio, demuestra que los microempresarios ubicados dentro del grupo 3 de sector calzado, no perciben el Marco Técnico Normativo de Información Financiera como un instrumento que Direccione o Regule la información financiera de las microempresas. Tal posición, se asume a partir de la interpretación de los testimonios aportados por los sujetos de estudio, pues ninguno de los entrevistados tiene una percepción clara sobre la aplicación del Marco Técnico Normativo de Información Financiera, ni del Decreto 2706/2012.

La mayoría de los testimonios recopilados demuestran la existencia de una confusión en relación a los conceptos de: valores devengados, transacciones en efectivo, contabilidad en valores de caja durante un cierto periodo al establecer su sistema de contabilidad, entre otros. Tal situación, revela que la percepción inicial de lo qué es y lo que direcciona y regula el Marco Técnico Normativo es confusa. Algunas de las respuestas encontradas se presentan a continuación: 
- "No sé cuál sea el Marco Técnico Normativo de Información Financiera para las Microempresas, no había escuchado antes hablar de esto" (P12BSM6MCN).

- "No sabe que directrices enuncia el Marco Técnico Normativo de Información Financiera" (P2BSM6MCN).

- "Es una forma de cómo se deben presentar los balances” (P2BC5MCN).

- “Desconozco la información” (P7BC5MCN).

- "No tengo conocimiento el Marco Técnico Normativo de Información Financiera” (P3BG3MCN).

- "No tengo conocimiento de esta información" (P5BG3MCN).

- "No se acerca del Marco Técnico Normativo de Información Financiera, de esa parte se encarga la contadora”. (P3BLB7MCN).

Otro elemento identificado en esta categoría es que los entrevistados perciben el Marco Técnico Normativo de Información Financiera y el Decreto 2706 de 2012, como un mecanismo que estandariza la información financiera, algunos testimonios donde esta categoría se hace evidente se presentan a continuación:

- "El papel de estandarizar la información" (P1BC8MCN).

- "La forma en que se presentan los balances financieros de la empresa” (P2BC8MCN1).

- "Unificar información para la fácil toma de decisiones" (P5BLB7MCN).

- “Estandarizar Información” (P6BSM6MCN).

- “Consolidar información” (P2BC5MCN).

- "Es una pauta de cómo se presentan los balances de una empresa" (P9BC5MCN1).

$\mathrm{Al}$ analizar los testimonios expuestos, se encuentra que la percepción de los sujetos objeto de la investigación está muy bien soportada desde lo normativo y propositivo: el Decreto 2706 de 2012 define el Marco Técnico Normativo de Información Financiera como un instrumento de los requerimientos de reconocimiento, medición, presentación e información a revelar de las transacciones y otros hechos y condiciones de los estados financieros.

No obstante, en este contexto cabría interrogarse hasta qué punto los propietarios de estas microempresas tienen claridad sobre la aplicación y objetivos del Marco Técnico Normativo de Información Financiera, lo cual es definitivamente un elemento clave para que las instituciones encargadas de aplicar esta normativa orienten acciones hacia la capacitación de los microempresarios sobre esta temática.

Percepción 3. El Marco Técnico Normativo de Información Financiera como mecanismo y oportunidad para la autoevaluación y el mejoramiento:

Otra categoría identificada, se relacionó con la percepción del Marco Técnico Normativo de Información Financiera como una oportunidad para el mejoramiento competitivo de las microempresas. En este aspecto destaca que aún cuando los propietarios no conocen el Marco Técnico Normativo de Información Financiera, si identifican el Decreto 2706/2012, pues sus contadores les habían aportado información al respecto. A continuación, se presentan los testimonios que soportan la percepción de la aplicabilidad del Decreto:

- "capacitación para poder dar interpretación al Decreto y al Marco Técnico Normativo en la Microempresa" (P5BG3MCN).

- "las funciones, los beneficios y la correcta aplicación del Marco Técnico Normativo de Información Financiera en las Microempresas" (P4BG3MCN).

- “...implementar el Marco Técnico Normativo de Información Financiera en las Microempresas para sacar los mayores beneficios que se puedan" (P4BB2MCN).

- “...asesoramiento sobre la aplicación del Marco Técnico Normativo de Información Financiera en las Microempresas y sus beneficios" (P2BSM6MCN). 
- "para tomar decisiones con base a los resultados" (P6BSM6MCN).

Los resultados expuestos, demuestran que los propietarios de de las microempresas, reconocen los beneficios de la aplicación del Marco Técnico Normativo de Información Financiera y del Decreto 2706/2012, como oportunidad de autoevaluación y mejoramiento empresarial. Sin embargo, también cabe mencionar que estos resultados no aportan información relacionada con las acciones y estrategias que las microempresas han asumido como muestra del mejoramiento de la competitividad empresarial.

Percepción 4. El Marco Técnico Normativo de Información Financiera no es conocido por los microempresarios, en consecuencia éste no genera efectos en las microempresas:

Esta categoría, permitió identificar si los microempresarios tienen desconocimiento acerca de la aplicación del Marco Técnico Normativo de Información Financiera. Al respecto, las respuestas de los sujetos de investigación se resumen en: "no conozco el Decreto", "no, lo sé", "no hemos aplicado esa norma de microempresas", "no hemos participado", "no producimos estados financieros", "no tenemos documentos ni soportes organizados", "no tengo conocimiento" o "yo lo he escuchado pero no tengo mayor conocimiento..."

Del análisis de los testimonios expuestos, se deduce que la percepción de los sujetos investigados es que la aplicación del Marco Técnico Normativo de Información Financiera no afectará el funcionamiento de sus empresas. Por ende, se requiere instrumentar un proceso formativo y de capacitación de los microempresarios sobre esta temática, dado que el incumplimiento de esta normativa conduce a la aplicación de sanciones, así como a la disminución de la competitividad empresarial.

Percepción 5. Efectos organizacionales que ha generado aplicación del Marco Técnico Normativo de Información Financiera para las microempresas del sector calzado:

A continuación se exponen los efectos organizacionales que ha generado la aplicación del Marco Técnico de
Información Financiera en las microempresas del sector calzado ubicadas en la comuna nueve de la Ciudad de Cúcuta. Con fines metodológicos, a partir de las respuestas de los sujetos de investigación, se procedió a construir las siguientes categorías: a) acciones a nivel empresarial y, b) acciones a nivel organizacional.

Las acciones a nivel empresarial abarcan las actividades, innovaciones y estrategias relacionadas con el Marco Técnico Normativo de Información Financiera que las microempresas han instrumentado en los últimos años. De acuerdo con la información suministrada por los propietarios de las microempresas objeto de estudio, estas acciones se resumen en:

- Lo qué se hace:

a. No hacen nada respecto a la aplicación del Marco Técnico Normativo de Información Financiera.

b. No se capacita ni al propietario ni a los contadores, así lo manifestaron tres (3) propietarios de las cuarenta y cinco (45) microempresas a las que se les aplico el cuestionario.

c. La aplicación del Marco Técnico Normativo de Información Financiera es una responsabilidad al contador.

- Lo qué se piensa hacer:

a. Preguntar nuevamente al contador sobre el tema en mención.

b. Buscar apoyo con los entes gubernamentales.

c. Buscar información y capacitarse.

d. Acudir a las Instituciones de Educación Superior para solicitar asesoría.

e. Indicar al contador que apliquen el Decreto 2706 de 2012 y, el Marco Técnico Normativo de Información Financiera.

f. Participar en seminarios y cursos de capacitación sobre la aplicación del Marco Técnico Normativo de Información Financiera.

g. Asesorarse con un contador sobre el tema.

Es importante resaltar en este punto, que el 93\% de los propietarios afirman que no tenían conocimiento del Decreto ni del Marco Técnico Normativo de Información Financiera que debían aplicar como microempresarios, y no han participado en seminarios, ni en procesos de capacitación sobre el tema. 
De otro lado, las acciones a nivel organizacional, comprenden todas las actividades, innovaciones o estrategias que se han desarrollado a nivel organizacional en los últimos años y, que se encuentren relacionadas con la implementación y aplicación del Marco Técnico Normativo de Información Financiera. $\mathrm{Al}$ respecto los resultados revelan:

- No han realizado la aplicación del Marco Técnico Normativo de Información Financiera.

- No se ha incentivado la capacitación para la aplicación del Marco Técnico Normativo de Información Financiera.

- Tres microempresas manifiestan el compromiso de aplicación del Marco Técnico Normativo.

- Manifiestan buscar apoyo Gubernamental y con Instituciones Educativas.

- No han escuchado acciones que realicen los Entes Departamentales ni Municipales, ni las universidades de la región.

Sobre este aspecto, resulta de interés señalar que el 93\% de los propietarios reportan que no tienen conocimiento sobre las acciones que desarrollan los entes Gubernamentales, Municipales, y las universidades de la Región sobre la aplicación del Marco Técnico Normativo de Información Financiera. Así mismo, se identificó que los microempresarios tienen total desconocimiento de la aplicación del Marco Técnico Normativo de Información Financiera, lo cual es producto de la falta de capacitación y formación para su correcta ejecución, la falta de organización de las microempresas, el insuficiente acceso a las nuevas tecnologías lo cual incide en la competitividad empresarial. Por ende, en vista de la necesidad de aplicar este Decreto, para el mejoramiento continuo de las microempresas, se requiere promover un proceso de capacitación de los microempresarios a través de los entes gubernamentales ubicados en la Ciudad de Cúcuta, así como de las instituciones de educación superior.

\section{Conclusiones}

Los resultados de la investigación demuestran, que los sujetos de estudio a los que se les aplicó el instrumento, no tienen conocimiento sobre el Marco Técnico de Información Financiera, así como de la instrumentación del Decreto 2706 en Colombia, en vista de que ambos son percibidos por un gran número de microempresarios como una herramienta de poca transcendencia pues no les aporta mayor beneficio en los aspectos administrativos, organizacional y contable de la empresa.

Como consecuencia de lo expuesto, se puede deducir que los objetivos trazados y esperados por el Estado con la aplicación del Decreto 2706, para adaptar las exigencias de internacionalización de la normativa contable, a través de la adopción de un régimen simplificado de contabilidad de causación no se han cumplido. No obstante, como aspecto significativo, cabe destacar que 3 de las 45 microempresarios entrevistados, manifestaron que su contador debía estar aplicando el Decreto en mención; mientras que los 42 restantes, expresó iniciativa e interés por capacitarse para la aplicación del Decreto.

Se comprobó igualmente que para algunos propietarios de las microempresas, el Marco Técnico Normativo de Información Financiera no presenta la importancia suficiente, ni el impacto necesario para el procesamiento y registro de la contabilidad en su negocio. Así mismo, se pudo comprobar que muchos de los comerciantes entrevistados no están preparados para enfrentar los cambios que implican la instrumentación de la nueva reglamentación en materia contable, pues manifestaron no estar capacitados para asumirlos y, la gran mayoría de los entrevistados no lleva contabilidad en la actualidad tal y como lo establece el Código de Comercio.

El trabajo realizado permite además constatar, que el suministro de información sobre el tema en mención, por parte de los entes gubernamentales ha sido escasa, y por ende, los microempresarios desconocen las implicaciones e impacto contable del MTNIF sobre sus empresas. De igual manera, no se evidencio, ni se reconoció, por parte de los microempresarios la aplicación de estrategias empresariales e innovaciones para la aplicación del MTNIF. 
Finalmente, la mayoría de los encuestados piensa en que es muy útil contar con el apoyo y capacitación de las Instituciones de Educación Superior sobre el tema de la aplicación del Decreto 2706/2012 y, su Marco Técnico Normativo de Información para las microempresas. En tal sentido, como aporte del presente trabajo de investigación se propone establecer una vinculación entre la Universidad Libre Seccional Cúcuta, y el sector productivo integrado por los microempresarios del calzado de la ciudad de Cúcuta, para a través del Centro de Emprendimiento y Desarrollo Empresarial Universidad Libre (CEDEUL) promover algunas estrategias de capacitación orientadas hacia:

- La capacitación de los microempresarios mediante el dictado de cursos de capacitación, seminarios y talleres orientados a destacar la importancia y obligatoriedad de la aplicabilidad del Decreto 2706/2012 y su Marco Técnico Normativo de Información Financiera.
- La promoción del desarrollo de las prácticas empresariales (administrativas - contables) de los estudiantes de la Facultad de Contaduría de los últimos semestres en las microempresas objeto de estudio.

- La elaboración de cartillas didácticas para dar a conocer el Decreto 2706 y su Marco Técnico Normativo, así como los alcances de su aplicación, ventajas y desventajas.

- La agrupación de las microempresas del sector calzado a través del CEDEUL, para establecer mecanismos de cooperación, manteniendo en cada una de estas organizaciones su independencia y autonomía, propendiendo por una colaboración en la búsqueda de un objetivo común, como es la aplicación del Marco Técnico Normativo de Información Financiera.

\section{Referencias}

Consejo de Normas Internacionales de Contabilidad (IASB). (2009). Norma Internacional de Información Financiera (NIIF) para Pequeñas y Medianas Entidades (PYMES). London: IFRS.

Consejo Técnico de la Contaduría Pública. (2012). Bases de conclusiones sobre el documento Proyecto de Norma de Información Financiera para las Microempresas. Recuperado de:

http://www.globalcontable.com/attachments/studies/basees_ conclusiones_microempresas.pdf

Congreso de Colombia. (2004). Ley 905. Recuperado de: http://www.secretariasenado.gov.co/senado/basedoc/ ley_0905_2004.html

Congreso de Colombia (2009). Ley $N^{o} 1314$, Recuperado de: $\quad$ https://www.superfinanciera.gov.co/SFCant/ NormativaFinanciera/ley1314_09.pdf

Gatto, Francisco; Ferraro, Carlos; Corcel Gloria \& Sourroille, Diego. (1993). Las PYMES en el Mercosur. Definiciones y primeras estimaciones. Buenos Aires: CEPAL.
González, Tania (2005). Problemas en la definición de microempresa. Revista Venezolana de Gerencia (10) 31, 408423.

koval, Santiago. (2012). Los niveles de la investigación cuantitativa en Ciencias Sociales. Recuperado de: http:// www.santiagokoval.com/2012/08/05/los-niveles-de-lainvestigacion-cuantitativa-en-ciencias-sociales/

Martínez, Miguel. (2006). La investigación cualitativa (síntesis conceptual). IIPSI (9)1, 123-146.

Ministerio de Comercio, Industria y Turismo. (2012). Decreto Número 2706. Bogotá.

Ministerio de Comercio, Industria y Turismo. (2013). Decreto Número 3019. Bogotá.

Thiebaut, Carlos. (1998). Conceptos fundamentales de la filosofía. Alianza Editorial, Madrid.

Tunal, Gerardo. (2003). El Problema de Clasificación de las Microempresas. Actualidad Contable (6) 7, 78-91. 